\title{
O PENSAMENTO de BAUMANIANO E OS PARADIGMAS dE MEDIAÇÃo dA INFORMAÇÃO
}

\author{
BAUMAN THOUGHT AND THE MEDIATION PARADIGMS OF INFORMATION
}

Mário Gouveia Junior ${ }^{1}$

RESUMO: Pretende verificar se a lógica baumaniana que trata do par de conceitos Liberdade e Segurança, nas relações entre indivíduo e sociedade, pode ser aplicada às relações de mediação e custódia vivenciadas pelos Sistemas de Informação. Trata-se de uma revisão de literatura. Apresenta como resultados a perspectiva de que o emergente Paradigma Póscustodial pode ser uma resposta ao dilema entre a preservação e o acesso à informação. Nesse sentido, a digitalização de conteúdos informacionais, naturalmente, seguidas de sua preservação em plataformas que se disponham a seguir padrões de armazenamento e recuperação de informação confiáveis pode representar a medida para que se possa obter o sucesso entre os pares de ambivalências paradigmáticas presentes nos serviços de mediação: custódia-acesso e segurança-liberdade de informação.

PALAVRAS-CHAVE: Sistemas de Informação. Segurança. Liberdade. Paradigma Pós-custodial.

ABSTRACT: It is intended to verify Bauman's theory, about the concepts Freedom and Security, regarding the relationship between individual and society, can be applied in relations of mediation and custody experienced by information systems. In methodological terms, it is about a literature review. As results is added that the prospect of the emerging paradigm Post-custodial can be an answer to the dilemma between preservation and acces to information. In that sense, scanning informational content, of course, followed by preservation on platforms that are willing to follow standards of reliable storage and retrieval of information may represent the extent to which one can obtain a success between pairs of paradigmatic present ambivalences in mediation services: custody-access and security-freedom of information.

KEYWORDS: Information Systems. Security. Freedom. Paradigm Post-custodial.

\footnotetext{
${ }^{1}$ Licenciado em História (UFPE). Especialista em Cultura Pernambucana (FAFIRE). Mestre em Ciência da Informação (UFPE). Doutorando em Informação e Comunicação em Plataformas Digitais (Universidade do Porto e Universidade Aveiro). gouveia historiador@yahoo.com.br
}

Submetido em: 19/03/2014 - Aceito em: 08/10/2014 


\section{INTRODUÇÃ̃o}

Acredita-se que a linguagem, muito provavelmente, tornou-se necessária quando os primeiros homens iniciaram relações de cooperação e intencionalidade de transmissão e compartilhamento de informação. A ausência de especialização para enfrentar o meio hostil e o medo dos inimigos os levou a um comportamento de proteção de seus grupos a partir de barulhos frequentes e grunhidos, que, gradualmente, podem ter-se desenvolvido em comunicação vocal (CAPRA, 2006).

A familiarização com as habilidades de entender, e de se fazer entender, contribuiu sobremaneira para a disseminação do conhecimento existente, que, por seu turno, engendrou cada vez maiores possibilidades de se aprender com experiências do outro e aprimorar noções e expectativas (GOUVEIA JUNIOR; GALINDO, 2012). Tal assertiva é corroborada por Ortega y Gasset (2006), quando este considera que o homem se diferencia dos tigres, por exemplo, devido ao seu poder de lembrar e sua capacidade de aprender com seus acertos, mas também com suas falhas e com as falhas dos seus semelhantes. Seria esta uma aprendizagem cumulativa e baseada na memória do erro, na sua divulgação e posterior busca pelo correto ou pela verdade. Vale lembrar que o certo carrega apenas temporariamente esse status, uma vez que é a incerteza que move a ciência, e as perguntas são mais priorizadas do que as respostas (PRIGOGINE, 2002).

Quando o homem caminhou da oralidade para a escrita, a assimilação e a interiorização dessa nova tecnologia, que representou o alfabeto fonético, transladaram o homem do mundo mágico da audição para o mundo neutro da visão (MCLUHAN, 1977). Essa magia referente à audição parece dialogar com a arte da narrativa, que apresentou indícios de extinção desde o surgimento do romance, essencialmente vinculado ao livro impresso e por ele difundido (BENJAMIM, 1994).

Antes da Revolução da Escrita, as memórias abrigavam-se na oralidade, contando com as "cabeças" e as "bocas" de todos os elementos de um grupo que fossem capazes de se expressar através da fala. Em meio a esses indivíduos, sobressaiam-se aqueles com maiores aptidões mnemônicas e comunicativas; os homens-memória, que registravam os eventos contemporâneos com a mesma habilidade com que recordavam à comunidade os eventos passados (LE GOFF, 2003). O problema é que a morte de um desses especialistas 
representava a perda de muita informação, sendo válido o provérbio indo-africano: "quando morre um velho, arde uma biblioteca".

Com o advento da escrita, e, sobretudo, com as inovações tecnológicas que permitiram a invenção e a posterior popularização da Imprensa, os grupos humanos passaram a comunicar ideias através de signos visuais e a produzir um registro perene destes, criando, assim, uma memória exterior à mente (MCGARRY, 1999). Essa demanda se faria necessária à medida que a quantidade de Informação se tornasse superior à capacidade humana de guardá-las todas na memória. Seria preciso, então, solucionar o problema do armazenamento de informações em suportes palpáveis; surgiam as memórias de papel e as necessidades por lugares de memória (GOUVEIA JUNIOR; GALINDO, 2012).

O referido acúmulo de testemunhos materiais era movido pelo sonho de armazenar em tais suportes todo o conhecimento produzido. Entretanto a lógica do acesso à informação, e os seus fluxos, se configuravam como uma espécie de privilégio concedido a poucos, o que denuncia o paradigma custodialista, patrimonialista, historicista e tecnicista (SILVA E RIBEIRO, 2011).

É muito pertinente que se mencionem os fluxos de Informação, tendo em vista que este trabalho objetiva discutir, dialogicamente, se a lógica baumaniana de pensar segurança e liberdade entre indivíduos em sociedade pode ser transportada para o dilema entre a preservação/custódia e o acesso/compartilhamento de conteúdos em Sistemas de Informação. Desse modo, a primeira parte deste artigo, contém breves considerações em torno do par de paradigmas que envolve as relações de mediação em Sistemas de Informação: custodialismo e pós-custodialismo. Na segunda seção, discute-se o pensamento baumaniano e a dicotimia existente entre segurança e liberdade; que serão fundamentais à compreensão do debate proposto para a terceira e última parte, que compreende uma tentativa de aproximação entre as ideias de Bauman (2003) e os postulados de Silva e Ribeiro (2011) no que tange os serviços de mediação dos Sistemas de Informação. 


\section{ENTRE A PRESERVAÇÃo e o ACESSO: PARADIGMAS}

Amparada nas Plataformas Digitais de Informação e Comunicação, veiculadas em tempo real, a Ciência da Informação e toda a literatura por ela produzida encontram-se imersas em constante evolução e ressignificação. Tal dinâmica, catalisada pelas mídias digitais, não está, contudo, restrita à academia, tendo em vista que a sociedade como um todo, tem recebido o impacto de sua frequência, ao mesmo tempo em que ela mesma, individual ou coletivamente, é responsável por sua construção, distribuição e acesso (GOUVEIA JUNIOR, 2012).

A facilidade de acesso a conteúdos cada vez mais extensos em um espaço temporal cada vez mais diluído, requer de seus utilizadores a triagem daquilo que lhe serve em um universo de possibilidades de acordo com suas necessidades. Nesse contexto, parece senso comum que a Informação, como matéria-prima para a tomada de decisões, desfruta, atualmente, de uma posição privilegiada perante a sociedade no tocante à organização e à tessitura de seus planos de ação. É assim que a Informação se apresenta como sinônimo de poder numa realidade em que seu fluxo é global, contínuo e veloz, e que estratégias de preservação, controle e acesso têm estado nos focos da notícia e na pauta de instituições públicas e privadas, bem como no campo das ciências da Tecnologia e da Informação e Comunicação (MENDEL, 2009).

Guardar informação para ulteriores recuperações, todavia, é uma tarefa que demanda ações sistemáticas. E tais práticas começaram a ser vivenciadas quando o volume de informação disponível tornou-se superior às capacidades humanas de armazenamento. Para tanto, ainda que nutrissem desconfianças em torno do dilema de Pharmacon, os suportes materiais se fizeram necessários à medida que representavam o remédio contra os esquecimentos de todos aqueles que não desfrutavam da prerrogativa do tão mítico quanto memorioso Funes (BORGES, 1975).

Desde o advento dos primeiros arquivos e bibliotecas de que se tem notícia até o colapso do Estado Nacional francês, no século XVIII, a Informação se configurava como elemento de teor sagrado, e, portanto, indisponível a quaisquer indivíduos. Nesse sentido, Umberto Eco (1998) fala das bibliotecas cuja função era a de não deixar ler, de esconder os livros daqueles que eram considerados os maiores inimigos dos bibliotecários, os causadores da indesejada entropia nos sistemas. Por mais que fosse possível localizar determinado 
volume, este não deveria chegar às mãos do leitor-inimigo que ousasse macular o caráter sagrado de um acervo.

Concebidos mediante a perspectiva de celebração, conservação e legitimação da hegemonia de um grupo que se sobrepunha política, econômica e socialmente à maioria, as instituições de missão memorial trataram de barrar certos movimentos de iconoclasia, por vezes, sugeridos quando triunfam revoluções (GOUVEIA JUNIOR, 2012). Foi justamente a partir desses esforços de manutenção do status quo, que o Estado e as classes dominantes forjaram redutos patrimoniais e custodialistas, os quais defendem uma ótica de pensamento que envolve perigo e valor, e situam o patrimônio entre a preservação e a posse material, espiritual, econômica ou simbólica (CHAGAS, 2005).

Esse panorama resume, sem esgotar, a definição do paradigma preservacionista e custodial denunciado por Silva e Ribeiro (2011). Este modelo de gestão e mediação de Sistemas de Informação apresenta como traços principais a sobrevalorização da guarda, conservação e restauro do suporte; a identificação com a preservação da cultura erudita e da memória oficial - a fonte legitimadora dos Estados-nação. Em tempo, há que se considerar que um paradigma pode ser definido como a pedra angular de todo um sistema de pensamento de uma sociedade e ao mesmo tempo o produto de todo um desenvolvimento cultural, histórico, civilizatório (MORIN, 2011).

Fernanda Ribeiro (1998) considera a Revolução Francesa como um novo marco na evolução da história dos arquivos, desde o pós-1789 chamados de Archives Nationales, não apenas no tocante à propriedade, mas, fundamentalmente, em relação às funções de conservação e manutenção dos documentos oficiais. Por outro lado, deve-se enfatizar que se o fim do Absolutismo francês acarretou a laicização do ensino e das práticas de gerenciamento de Informação, em certa medida, essa Revolução não foi capaz de dessacralizar o acesso à informação, tendo em vista a emergência do paradigma custodial, histórico-patrimonialista e tecnicista. Tal paradigma, ainda predominante, apresenta como contradição interna a preservação do patrimônio, apregoado como um da coletividade, que, no entanto, por vezes, não tem o devido acesso a essa patrimônio.

Uma possibilidade de resposta a essa contradição pode ser o paradigma póscustodial, informacional e científico, marcado pela valorização da Informação como um fenômeno social; pela prioridade máxima dada ao acesso à Informação através da intensificação de políticas pautadas em seu compartilhamento no âmbito científico e 
tecnológico; pela conscientização dos fluxos informacionais; pelo livre acesso às redes de Informação; pela busca da igualdade de oportunidades para todos os cidadãos; e pelo respeito à diversidade cultural e linguística na criação de conteúdos (SILVA; RIBEIRO, 2011).

É pertinente considerarmos em relação ao paradigma custodial, o mais antigo, que este, em certa medida, ainda parece vigorar em grande parte das instituições de memória onde a desejada universalização da cordialidade da informação ainda é um sonho distante. Desse modo, o paradigma pós-custodial ainda aparece como estado de exceção. Até por que “a transição de um paradigma para outro não ocorre por ruptura; é gradual, tensa e está em curso" (SILVA; RIBEIRO, 2011, p.64).

Note-se que o trabalho em pauta não visa diminuir a importância da custódia, mas há que se considerar que esta só se legitima se apresentar como finalidade o acesso àquele conteúdo que se pretende preservar. Nesse contexto, preservação e acesso são verbos que devem ser conjugados de modo complementar e não antagônico.

\section{SEGURANÇA E LIBERDADE: DOS SUJEITOS ÀS INSTITUIÇÕES}

Em suas considerações sobre comunidade e identidade, e as respectivas correlações entre segurança e liberdade, Bauman (2003) afirma que estes são dois valores igualmente preciosos e desejados, mas que nunca podem ser totalmente equilibrados e obtidos sem atritos. A incompatibilidade de ambos os conceitos transparece quando se percebe que a promoção da segurança invariavelmente requer o sacrifício da liberdade, enquanto esta só pode ser ampliada à custa da segurança.

É assim que, de acordo com Bauman (2003), segurança e liberdade denotam a ambivalência da vida, já que a presença absoluta de uma em detrimento da total ausência da outra, fomentará situações indesejáveis. O conceito de ambivalência pode ser apontado como a presença concomitante de juízos que se contradizem em relação a um mesmo objeto. Tal situação faz com que um indivíduo ou um grupo se encontre imerso em constante tensão.

Em tempo, segundo o próprio Bauman (2003), segurança sem liberdade é escravidão; liberdade sem segurança é caos. Em muitos momentos da história das civilizações o temor 
que se configurava diante de uma iminente ameça de desagregação fomentou, de certa forma, retrocessos no que concerne as relações sociais e econômicas. Aprende-se na escola, por exemplo, que o colpaso do Império Romano do Ocidente e as ocupações dos povos ditos bárbaros, entre outros fatores, acabou por levar a Europa ocidental a um regime sóciopolítico-econômico com muitas restrições de liberdades, que ficou conhecido como Feudalismo.

A ambivalência segurança-liberdade também pode ser ilustrada com a agonia de Tântalo, filho de Zeus e Plutó, que fora castigado pelos deuses do Olimpo por adquirir e compartilhar um conhecimento a que nem ele nem os mortais como ele deveriam ter acesso. De modo análogo, a alegoria bíblica que apresenta a expulsão de Adão e Eva do Pparaiso revela que o primeiro casal teria transgredido o que fora determinado pelo Criador e provado do Fruto do Conhecimento. A dor e o labor seriam a sua punição.

O livre-arbítrio é uma maravilhosa concessão, que, no entanto, coloca o indivíduo a mercê de suas consequências. A moral da(s) história(s) é que a felicidade e o conforto só são possíveis quando caminham ao lado da ignorância ou da ausência de pensamento crítico-eação. Dissera Platão que a saída da caverna, invariavelmente, causaria desconforto aos olhos e ao espírito; é preciso reaprender a enxergar, a perceber o outro mundo, que não é o das sombras, mas o da luz e da verdade - que liberta. Aquele que tenta revelar aos outros essa verdade é passível de represálias por parte de todos aqueles que preferem manter o poder simbólico (BOURDIEU, 1989), que, em certa medida, representa segurança.

A ideia de comunidade tratada por Bauman (2003), sugere vigilância e supervisão por parte dos dirigentes de determinado grupo da mesma forma que demanda aquiescência e resignação da maioria. Ratifique-se, nesse sentido, que, para o indivíduo, fazer parte de uma comunidade é socialmente confortador, uma vez que, inserido em um grupo, pode-se desfrutar de uma sensação de força, naturalmente vivenciada a expensas de sua autonomia.

Insurgir-se contra a dominação traz como consequências a transformação das relações de poder (CASTELLS, 2013), o que, dependendo do grau de não aceitação ao poder que se impunha, pode acarretar o colapso da ideia de comunidade, substituída pela ideia de identidade (BAUMAN, 2003). À medida que as identidades - e com ela as individualidades - emergem, o homem coletivo tende a se aproximar da ideia de sociedade. Esta, ao contrário da comunidade, evidencia-se enquanto estrutura social que comporta

n.1


valores e interesses contraditórios provenientes de conflitos e negociações entre diversos atores sociais, na maioria das vezes, opostos (CASTELLS, 2013).

As práticas informacionais, pensadas como um processo resultante de uma ação socialmente partilhada através de criticidade e autonomia, são constituídas mediante produção, transferência, aquisição e significação por parte dos sujeitos, deixando de se apresentarem como meros veículos de ideologias. Isso porque, tal como a informação, a memória pode atuar como instrumento de dominação e domesticação dos homens, mas também denota a possibilidade de se constituir em ferramenta imprescindível à sua libertação, conforme pontua Le Goff (2003). Nesse sentido, de acordo com a teoria da complexidade, decorre que a própria autonomia se alimenta da dependência, uma vez que, para se definir autônomo, o sujeito precisou aprender uma linguagem, uma cultura e um saber que já se lhe teria sido disposto e imposto (MORIN, 2011).

A ideia baumaniana de comunidade sugere maior agregação, e portanto maior dependência dos membros em relação ao grupo. Neste caso, o sentimento de liberdade aparenta ser menos importante do que o de segurança. A ideia de sociedade, por sua vez, dialoga com um sentimento de diversidade, de conflito, interrompido apenas graças a acordos temporários. $\mathrm{O}$ discurso oficial, então, caracteriza-se mais pela coerência do que pelo consenso.

Se, de acordo com Bauman (2003), no tocante às relações indivíduo-comunidade, nunca se encontrará uma solução perfeita para a ambivalência segurança-liberdade, será que o mesmo se poderia afirmar das relações de mediação de serviços de Informação? A dúvida surge diante da constatação de que os conceitos de segurança e liberdade estão muito presentes nas preocupações e práticas de gestores de informação. Nessa perspectiva, como se pode gerir informação sem que se pensem políticas de preservação? Da mesma forma, qual seria o objetivo de preservar determinado acervo se este não apresentasse valor social? Só tem valor aquilo que se pode utilizar; que dialoga com a liberdade de acesso.

É com base em tais reflexões que custódia e acesso de Informação se ligam às perspectivas de segurança e liberdade. O paradigma custodialista pôde emergir e se consolidar, até os dias atuais, em virtude do pensamento de que as memórias precisavam ser mantidas para a posteridade, ainda que a custa da ausência de acesso. O paradigma póscustodial, por seu turno, não nega a importância das iniciativas de preservação ocorridas no passado e na atualidade, mas enxerga a importância do compartilhamento de conteúdos 
informacionais e entende o usuário como elemento importante desse processo. Haveria, então, possibilidades se não de uma ambivalência entre segurança e liberdade da informação, ao menos de uma dialógica para os Sistemas de Informação?

\section{AMBIVAlÊnCIA OU DialógICA PARA OS SISTEMAS dE INFORMAÇÃo?}

O desenvolvimento das instituições e organizações depende tanto de uma eficiente utilização do recurso informação quanto da capacidade de armazená-lo e recuperá-lo. Os desafios que se apresentam às organizações, neste caso, demandam, para além de uma aparelhagem tecnológica, um reequacionamento da estrutura organizacional (PINTO; SILVA, 2005). Nesse sentido, os chamados sistemas artificiais convencionais implicam a intervenção humana e suas relações organizativas e dinâmicas, dispostas de modo a tecer uma rede. A apreensão, (re)construção e disseminação de saberes depende, necessariamente, da intenção do autor e da ação do leitor, já que se pode pensar que toda ideia transcrita na forma de documento se justifica com base na suposição de que esta será lida; a leitura desse documento, naturalmente acompanhada de interpretação, é que poderá vir a se tornar um saber (SILVA, 2006).

Uma organização forte, com um Sistema de Informação bem estruturado, poderá encontrar na cooperação, na construção de redes de organizações, no uso efetivo do conceito de "rede" a plataforma para responder à economia global, quer a partir da própria capacidade de iniciativa quer como resposta a incentivos estatais (SILVA, 2006). A ideia de Sistema de Informação, que se pode designar, ainda que genericamente, como um conjunto de aplicações que partilham dados entre si, apresenta-se, desse modo, como o fruto da relação transdisciplinar suscitada pela lógica sistêmica.

Em um campo de estudo que se dedica à tecnologia, desenvolvimento, uso e gerenciamento da Informação, um Sistema de Informação se apresenta como uma área fragmentada e multifacetada, cujo foco de atuação reside em questões de análise organizacional e se configura como um fenômeno técnico e social. O que evidencia a ideia de uma interciência, que tem como integrante a Ciência da Informação (SILVA, 2006).

Apresentou-se na sessão anterior, ainda que brevemente, o conceito de ambivalência como pensamentos ou juízos contrários que se apresentam de modo a criar uma sensação

n.1


perene de tensão. Esse estado de coisas pode levar ao entendimento de que ideias contrárias podem encontrar uma síntese a partir da dialética. Todavia defende-se que a melhor forma de se buscar o entendimento acerca de uma forma de pensar não seja o confrontamento de pontos de vista que se antagonizam, mas a confluência destes. Nesse particular a dialogia proveniente da teoria da complexidade pode apresentar um contributo maior. Há que se considerar, a princípio, que o pensamento complexo comporta um tensão permanente entre a busca por um saber não fragmentado e não redutor e o reconhecimento da natureza inacabada e da incompletude de qualquer conhecimento (MORIN, 2011).

Deve-se registrar também que não se deve incorrer no erro de acreditar que o pensamento complexo se reduz à ciência ou à filosofia; antes, a complexidade permite a comunicação entre esses dois campos do conhecimento, servindo-lhes de ponte. O que não significa, entretanto, que a complexidade atue de modo a diminuir as incertezas ou a conceder respostas. Ordem e desordem se sucedem, denunciando que o universo, e cada uma de suas partes, encontra-se num estado de entropia constante, delineando um equilíbrio dinâmico. Ideias opostas, desse modo, podem apresentar muito mais pontos de contato do que se poderia imaginar.

Partindo dessa lógica, pode-se pensar que, no âmbito das relações de mediação de informação, o conjunto de pares segurança-liberdade e custódia-acesso pode ser conciliados. E nesse contexto, os Sistemas de Informação têm contado com um forte aliado no sentido de tornar possível essa relação complexa entre a segurança e a liberdade, entre a custódia e o acesso: as plataformas digitais, isto é, a digitalização de conteúdos informacionais. É importante considerar, nessa perspectiva, que a preocupação com a Preservação Digital deve estar presente em todas as inciativas que se destinem a promover o acesso à informação digital (SAYÃO, 2005). A fragilidade e o caráter efêmero de muitos suportes que rapidamente entram em obsolescência face o advento de novas tecnologias.

A criação de um repositório institucional que garanta a preservação e o acesso à informação - para além das iniciativas de produção de backup e cópias de redundância - não é o bastante para conciliar a ambivalência entre a segurança e a liberdade de informação. É fundamental garantir o acesso continuado e a longo prazo à memória informacional em formato digital, monitorando constantemente os dados armazenados. Deve-se pensar, do mesmo modo, em uma Política Institucional de Informação que adote rotineiros

n.1


procedimentos de Análise de Risco, identificação e mitigação permanente dos perigos que possam ameaçar os objetos digitais (SAYÃO, 2005).

Iniciativa mais abrangente do que a Preservação Digital, a Curadoria Digital se destaca no âmbito do gerenciamento de documentos digitais por incluir atividades que contemplam o ciclo de vida desses documentos, como a gestão de dados, ou seja, planejamento, boas práticas na digitalização, seleção dos formatos, garantia de disponibilidade e recuperação posterior (SIEBRA et al, 2013).

\section{CONSIDERAÇÕES FINAIS}

À medida que os Sistemas de Informação assumem o entendimento e o compromisso de que a sua função e o seu valor social estão alocados em práticas de disseminação de Informação tanto em relação aos seus usuários quanto entre si mesmas, começa a se configurar a assunção do novo paradigma que se apresenta dotado de natureza pós-custodial, informacional e científica. O que, como foi afirmado, não representa a exclusão ou supressão do modelo custodialista, ainda predominante.

Caminha ao lado desse novo paradigma o importante entendimento de atuação conjunta, isto é, o desenvolvimento de trabalhos que integram e incentivam instituições distintas, que se aproximam e conseguem benefícios mútuos mediante um fluxo de informação partilhado. Acrescente-se que atualmente, e cada vez mais, a notoriedade não reside mais naquilo que as pessoas e instituições são capazes de guardar, mas naquilo que possam compartilhar. O que pode levar a se pensar a atualidade como a Era do Acesso e dos Sistemas, tendo em vista as tessituras sistêmicas e reticulares que se apresentam, por exemplo, na chamada Web 2.0.

Vale enfatizar que pensar sistemicamente significa defender uma visão nãomecanicista e pós-cartesiana, afastando-se das noções reducionistas, deterministas e analíticas de se pensar o universo-como-máquina. Significa pensar em redes, em teias de interconexões. O universo, então, é percebido como um todo dinâmico, indivisível, cujas partes estão interrelacionadas, enquanto que a ordem, a reversibilidade e o equilíbrio estático 
também tendem a ser evitadas pelo fato de não corresponderem às realidades das ciências, muito menos às dinâmicas sociais.

Essa tessitura organísmica engendra a perspectiva de que nenhuma sociedade é capaz de sobreviver como sistema de ação se o organismo não se adapta a um meio ecológico, além do que lhe é destinado. Tal concepção pode ser traduzida a partir do entendimento de que um organismo que não se reinventa ante a adversidade está fadado ao desaparecimento.

Em meio ao embate dicotômico entre dominação e libertação, que se apresenta nesse trabalho, deve-se ressaltar que nem toda assimilação do hegemônico pelo subalterno acarreta necessariamente submissão. Do mesmo modo, a simples recusa não é sinônimo de resistência. Por outro lado, quando a construção coletiva de uma memória informacional se impõe ao Poder Simbólico, a autonomia supera a alienação e se pode pensar em desenvolvimento social. Um desenvolvimento que se dedique a uma distribuição mais equitativa dos bens patrimoniais das nações entre todos os seus cidadãos.

A digitalização de conteúdos informacionais, naturalmente, seguidas de sua preservação em plataformas que se disponham a seguir padrões de armazenamento e recuperação de informação confiáveis pode representar a medida para que se possa obter um relativo sucesso entre os pares de ambivalências paradigmáticas presentes nos serviços de mediação: custódia-acesso e segurança-liberdade de informação. Dessa forma, pode-se chegar ao entendimento de que a criação e o desenvolvimento de comunidades sustentáveis que abriguem ambientes socioculturais onde se possam satisfazer as necessidades de informação, sem diminuir as chances das gerações futuras, corrobora com os ideais adotados a partir da assunção da responsabilidade coletiva de ser um bom ancestral.

\section{REFERÊNCIAS}

BAUMANN, Z. Comunidade: a busca por segurança no mundo atual. Rio de Janeiro: Jorge Zahar, 2003.

BENJAMIM, W. Magia e técnica, arte e política: ensaios sobre a literatura história da cultura. 7.ed. São Paulo: Brasiliense, 1994.

BORGES, J. L. Funes, o memorioso. In: Ficções. São Paulo: Círculo do Livro, 1975. 
BOURDIEU, P. O poder simbólico. Rio de Janeiro: Bertrand, 1989.

CAPRA, F. A teia da vida: uma nova compreensão científica dos seres vivos. São Paulo: Cultrix, 2006.

CASTELLS, M. O poder da comunicação. Lisboa: Fundação Calouste Gulbenkian, 2013.

CHAGAS, M. S. Casas e portas da memória e do patrimônio. In: GONDAR, J; DODEDEI, V. L. (org.). O que é memória social? Rio de Janeiro: Contra Capa Livraria / Programa de Pós-Graduação em Memória Social da Universidade Federal do Estado do Rio de Janeiro, 2005 .

ECO, U. A biblioteca. 4. ed. Lisboa: Difel, 1998.

GOUVEIA JUNIOR, M.; GALINDO, M. Sistemas memoriais como disseminadores de informação. Transinformação, Campinas, v. 24, n. 3, p. 207-217, set./dez. 2012.

Disponível em: 〈http://www.scielo.br/pdf/tinf/v24n3/a05v24n3.pdf〉. Acesso em: 12 jan. 2014.

GOUVEIA JUNIOR, M. A gestão da memória: as políticas públicas culturais e a situação dos museus no estado de Pernambuco. 2012. 212f. Dissertação (Mestrado em Ciência da Informação) - Universidade Federal de Pernambuco, Programa de PósGraduação em Ciência da Informação, Pernambuco, 2012. Disponível em: <https://www.ufpe.br/ppgci/images/documentos/disserta/2011\%20mario.pdf $>$. Acesso em: 14 jan. 2014.

LE GOFF, J. História e memória. 5. ed. Campinas: Unicamp, 2003.

McGARRY, K. O contexto dinâmico da informação. Brasília: Briquet de Lemos, 1999.

McLUHAN, M. A galáxia de Gutenberg: a formação do homem tipográfico. São Paulo: Nacional, 1977.

MENDEL, T. Liberdade de informação: um estudo de direito comparado. 2. ed. Brasília: UNESCO. 2009.

MORIN, E. Introdução ao pensamento complexo. 4. ed. Porto Alegre: Sulina, 2011. 
ORTEGA Y GASSET, J. A rebelião das massas. 2. ed. São Paulo: Martins Fontes, 2006.

PINTO, M. A.; SILVA, A. M. Um modelo sistémico e integral de gestão da informação nas organizações. In: CONGRESSO INTERNACIONAL DE GESTÃO DA TECNOLOGIA E SISTEMAS DE INFORMAÇÃO, 2., 2005, São Paulo. Anais... São Paulo: FEA/USP, 2005. Disponível em: 〈http://ler.letras.up.pt/uploads/ficheiros/3085.pdf>. Acesso em: 04 fev. 2014.

PRIGOGINE, I. As leis do caos. São Paulo: UNESP, 2002.

RIBEIRO, F. O acesso à informação nos arquivos. 1998, 847f. Dissertação (Doutorado em Arquivística) - Universidade do Porto, Faculdade de Letras, Porto, 1998. Disponível em: <http://ler.letras.up.pt/site/default.aspx?qry=id06id131\&sum=sim>. Acesso em: 15 mar. 2014.

SAYÃO, L. F. Preservação digital no contexto das bibliotecas digitais: uma breve introdução. In: MARCONDES, C. H. et al (Org.). Bibliotecas digitais: saberes e práticas. Salvador: UFBA, p. 115-145, 2005.

SIEBRA, S. A. et al. Curadoria digital: além da questão da preservação digital. In: ENCONTRO NACIONAL DE PESQUISA EM CIÊNCIA DA INFORMAÇÃO, 14., 2013, Florianópolis. Anais... Florianópolis: UFSC, 2013. Disponível em:

<http://enancib.sites.ufsc.br/index.php/enancib2013/XIVenancib/paper/viewFile/317/320>. Acesso em: 9 fev. 2014.

SILVA, A. M. A informação: da compreensão do fenómeno e construção do objecto científico. Porto: CETAC.COM, Edições Afrontamentos, 2006.

SILVA, A. M.; RIBEIRO, F. Paradigmas, serviços e mediações em Ciência da Informação. Recife: Néctar, 2011.

\section{Como citar este artigo:}

JUNIOR, Mário Gouveia. O pensamento de baumaniano e os paradigmas de mediação da informação. Rev. digit. bibliotecon. cienc. inf., Campinas, SP, v.13, n.1, p.156-169, jan/abr. 2015. ISSN 1678-765X. Disponível em: <http://www.sbu.unicamp.br/seer/ojs/index.php/rbci>. Acesso em: 31 Jan. 2015. 